\title{
Strength Theory Model of Unsaturated Soils with Suction Stress Concept
}

\author{
Pan Chen, Changfu Wei, Jie Liu, and Tiantian Ma \\ State Key Laboratory of Geomechanics and Geotechnical Engineering, Institute of Rock and Soil Mechanics, \\ Chinese Academy of Sciences, Xiaohongshan, Wuchang, Wuhan, Hubei 430071, China
}

Correspondence should be addressed to Changfu Wei; cfwei@whrsm.ac.cn

Received 24 June 2013; Revised 12 September 2013; Accepted 18 September 2013

Academic Editor: Pengcheng Fu

Copyright (C) 2013 Pan Chen et al. This is an open access article distributed under the Creative Commons Attribution License, which permits unrestricted use, distribution, and reproduction in any medium, provided the original work is properly cited.

\begin{abstract}
A theoretical model is developed for describing the strength property of unsaturated soils. The model is able to predict conveniently the strength changes of unsaturated soils undergoing repeated changes of water content. Suction stress is adopted in the new model in order to get the sound form of effective stress for unsaturated soils. The shear strength of unsaturated soils is dependent on its soil-moisture state based on the results of shear experiments. Hence, the parameters of this model are related tightly to hydraulic properties of unsaturated soils and the strength parameters of saturated soils. The predictive curves by the new model are coincident with experimental data that underwent single drying and drying/wetting cycle paths. Hence, hysteretic effect in the strength analysis is necessary to be considered to predict the change of shear strength of unsaturated soils that underwent drying/wetting cycles. Once the new model is used to predict the change of shear strength, lots of time could be saved due to avoiding heavy and complicated strength tests of unsaturated soils. Especially, the model can be suitable to evaluate the shear strength change of unsaturated soils and the stability of slopes experienced the drying/wetting cycles.
\end{abstract}

\section{Introduction}

The change of soil strength is very important to evaluate the stability of slopes and road embankment. In this case, the strength model of unsaturated soils is always concerned in geotechnical engineering. Until now, many researchers have shown that the shear strength of unsaturated soils was tightly related to soil-moisture state [1-3]. The strength of unsaturated soils will increase or decrease during the intermittent precipitation and fluctuant water tables $[4,5]$. Hence, a new model should be necessarily developed, in which the change of soil strength can be reasonably predicted under the repeated change of water content. The model will be critical to analyze these problems that soil slopes become destabilized during the intermittent rainfall process.

The theoretical model for shear strength of unsaturated soils is generally developed based on the concept of effective stress, which is similar to the equation of shear strength of saturated soils. There are two types of description for effective stress of unsaturated soils that are prevalent in the literature. One type bases on the single stress variable [6] and the other on the double stress variable [7]. The equations of shear strength are given in Formulas (1) and (2), respectively, as follows:

$$
\begin{gathered}
\tau=c^{\prime}+\left[\sigma-p^{N}+\chi\left(p^{N}-p^{W}\right)\right] \tan \varphi^{\prime}, \\
\tau=c^{\prime}+\left(\sigma-p^{N}\right) \tan \varphi^{\prime}+\left(p^{N}-p^{W}\right) \tan \phi^{b},
\end{gathered}
$$

where $\tau$ is the shear strength; $c^{\prime}$ is the cohesion at the saturated state; $\sigma$ is the normal total stress; $\varphi^{\prime}$ is the effective internal friction angle; and $p^{N}$ and $p^{W}$ are the pore air pressure and pore water pressure, respectively. There are two parameters $\chi$ and $\phi^{b}$ in Formulas (1) and (2) which cause the difference of strength equations in form between saturated soils and unsaturated soils. $\chi\left(p^{N}-p^{W}\right) \tan \varphi^{\prime}$ and $\left(p^{N}\right.$ $\left.p^{W}\right) \tan \phi^{b}$ are the change of shear strength arising by the change of matric suction (water content) in unsaturated soils. On the one hand, $\chi$ in single stress variable framework will change with the degree of saturation $S_{r}$. But the results of some experiments show that the relationship is not unique 
between $\chi$ and $S_{r}[1,8] . \chi$ is strongly depended on the soil structure and soil-moisture state. On the other hand, the definition of the two-state variable exists some confusion in the scales from the view of continuum mechanics [9]. Normal stress loads on the skeleton of soils, but matric suction stresses on the air-water interface. Unfortunately, the two stress state variables are treated as stress variables acting on the representative elementary volume for the soils (REV). In Formula (2), the relationship of $\phi^{b}$ and matric suction $s_{c}\left(s_{c}=p^{N}-p^{W}\right)$ is nonlinear for the same soil [10]. And the functional relation is different for each type of soil between $\phi^{b}$ and $s_{c}$. Vanapalli et al. [10] proposed an empirical relation for calculating $\phi^{b}$ based on experiments of unsaturated soils. Khalili and Khabbaz [11] and Kayadelen et al. [12] gave different strength models based on the analysis of effective stress, respectively. Other forms of strength model are also found in the literature [13-15].

Although the existing models of shear strength have been used to analyze the geotechnical problems by many researchers, some problems may come out in practical application. Firstly, the parameters $\chi$ and $\phi^{b}$ in these formulas are not easy to be directly determined through the experiments of unsaturated soils. Secondly, the physical basis of these formulas is not definite. Hence, it could be suitable for some soils, but it is difficult to be adapted for other soils under different soil-moisture conditions. Thirdly, matric suction is one of the main variables in the expression of soil strength. There are some difficulty questions in the measurement of matric suction, which limit the development of experimental technology in laboratory and field conditions, such as cavitation phenomenon [16]. The application of these models is perhaps not reasonable to evaluate some problems in the field. Last but not least, most of the equations were limited to be used under only the drying process of unsaturated soils. But the strength characteristics of unsaturated soils are different which underwent the drying and wetting processes due to the existent of hysteretic effect at varying water content conditions [17].

Focusing on these problems of the existing shear strength models, a new model will be developed to describe the strength property of unsaturated soils. A conception of suction stress is introduced in order to modify the formula of effective stress of unsaturated soils. Based on the modified formula of effective stress, the formula of shear strength can be obtained using Mohr-Coulomb's theory. Shear strength envelope of unsaturated soils is unique on the plane with modified effective stress and shear strength at different matric suction or water content states. Then the soil-water retention curve is used to replace empirical parameters $\chi$ and $\phi^{b}$. Therefore, the strength of unsaturated soils can be predicted by the measurement of water content, which is easy to be determined both in the laboratory and field. In order to explore the strength property of unsaturated soils that underwent drying/wetting cycles, the hysteretic model (ISVH) [18] is introduced. The new model is able to simulate the strength evolution of unsaturated soils under repeated hydraulic paths. Lastly the predictive results from the model are compared with experimental data.

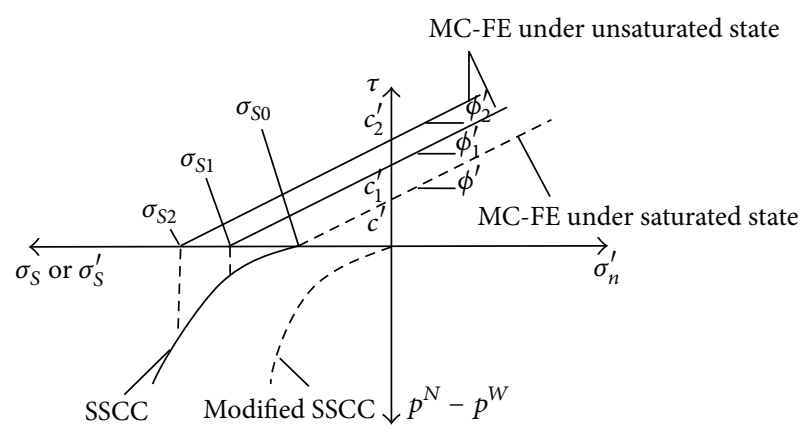

FIgURE 1: Suction stress characteristic curve from Mohr-Coulomb failure envelopes.

\section{The Concept of Suction Stress and Suction Strength}

2.1. The Concept of Suction Stress. Based on the analysis of the composites of microscopic forces in details, Lu and Likos [19] defined suction stress which is the macroscopic expression of different interactions in microscale (such as physicalchemical force, van der Waals force, electrical double-layer repulsion, and surface tension). The theoretical basis of the suction stress has been discussed by Lu and Likos [19]. Here, the method for obtaining suction stress is given from direct shear test and triaxial shear test of unsaturated soils. Traditionally, the data of shear strength under different normal stresses are plotted on the plane of normal effective stress $\sigma_{n}^{\prime}$ and shear strength $\tau$ or net mean effective stress $p^{\prime}$ and deviatoric stress $q$, seen in Figure $1 . c^{\prime}, c_{1}^{\prime}$, and $c_{2}^{\prime}$ are the intercept that Mohr-Coulomb failure envelops (MC-FE) and cut $\tau$-axis. $c^{\prime}, c_{1}^{\prime}$, and $c_{2}^{\prime}$ are called effective cohesion under saturated state and unsaturated state, respectively. $\varphi^{\prime}$, $\varphi_{1}^{\prime}$, and $\varphi_{2}^{\prime}$ are effective internal friction angle at different saturated state. The cohesion is the bond force or attractive effect among soil particles. The intercept on the $\tau$-axis gives the frictional action among soil particles. It is puzzled that the intercept can be called cohesion. Further, the intercept on the $\tau$-axis cannot fully represent the bond strength among the soil skeletons. Actually, the intersection is the attractive effect that MC-FE is prolonged and cuts the $\sigma_{n}^{\prime}$-axis, which can be expressed by $\sigma_{S}$, called suction stress by Lu and Likos [19]. The formula of suction stress can be given from direct shear test as follows:

$$
\sigma_{S}=\frac{-c^{\prime}}{\tan \varphi^{\prime}}
$$

The suction stress can be obtained by Formula (3) at different water content state. The relationship of suction stress and matric suction is called suction stress characteristic curve (SSCC). It is to be noted that suction stress is not zero for fine grain soils under saturated state, called $\sigma_{S 0}$. The original SSCC needs to be modified by the suction stress $\sigma_{S 0}$ to go through the origin, which is consistent with soil-water retention curve (SWRC), seen in Figure 1. 


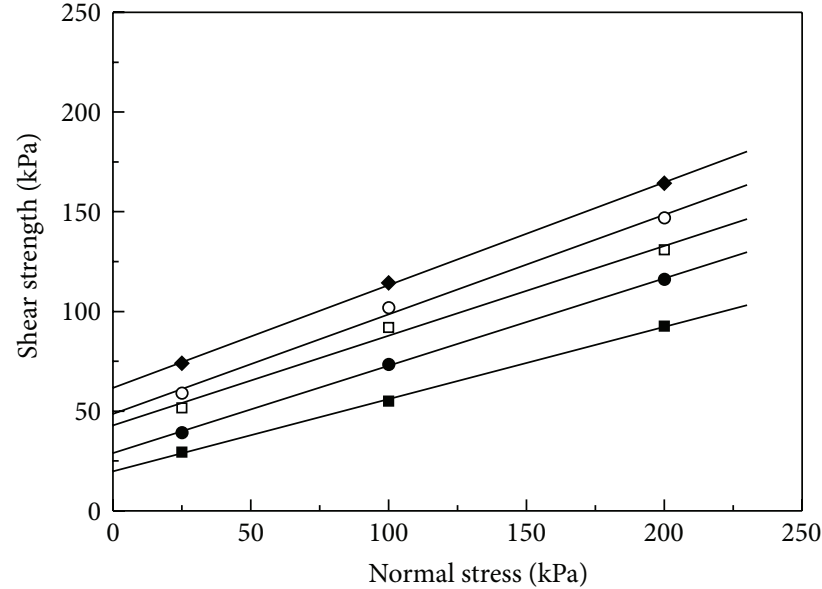

- Matric suction $s_{c}=50 \mathrm{kPa}$

- Matric suction $s_{c}=100 \mathrm{kPa}$

口 Matric suction $s_{c}=200 \mathrm{kPa}$

- Matric suction $s_{c}=350 \mathrm{kPa}$

- Matric suction $s_{c}=500 \mathrm{kPa}$ Fitting curves

(a) Shear strength envelops at drier than optimum water content

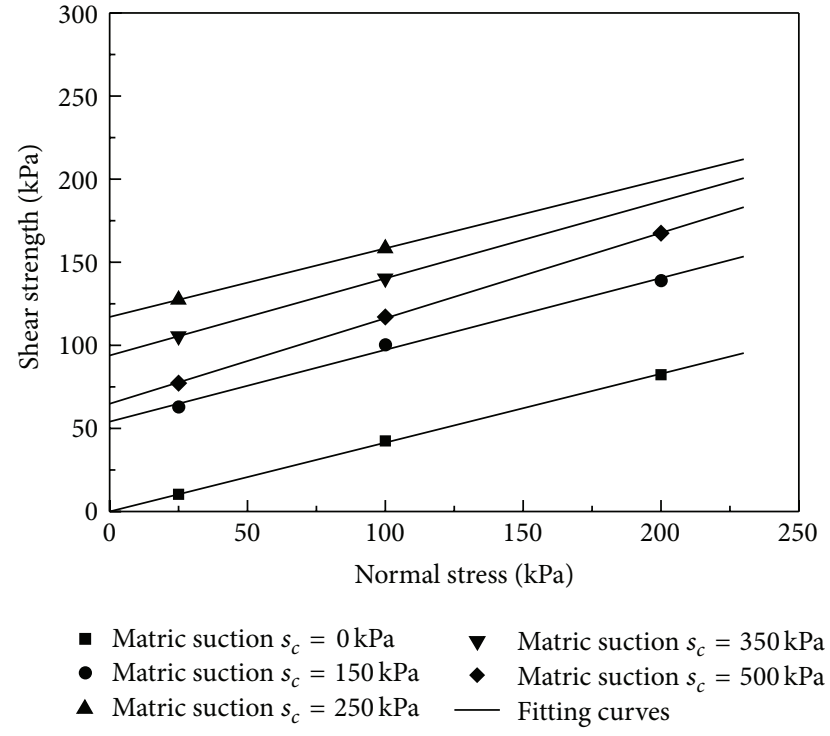

(b) Shear strength envelops at wetter than optimum water content

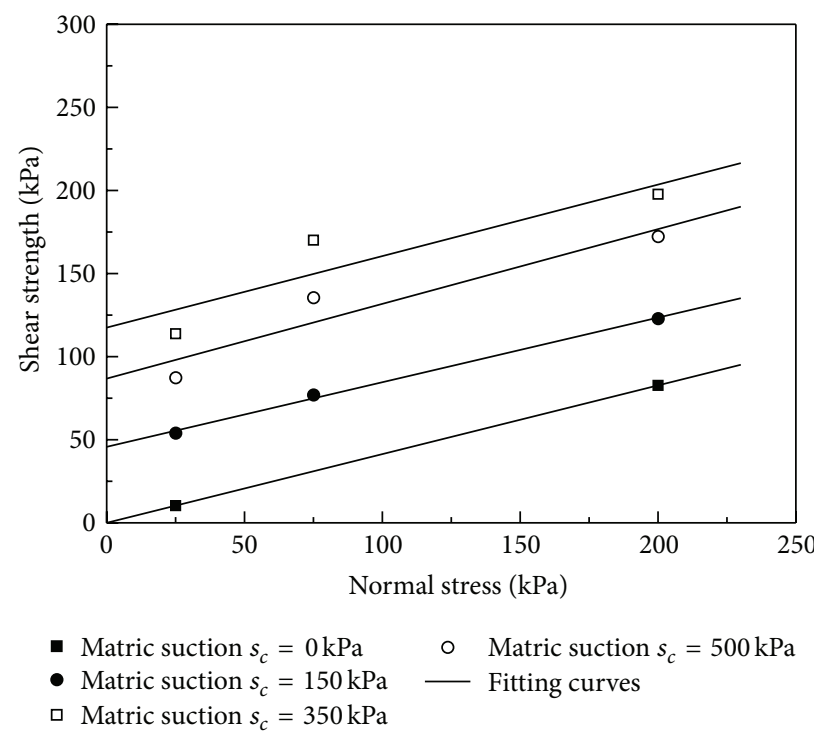

(c) Shear strength envelops at optimum water content

FIGURE 2: The curves of normal stress and shear strength at different initial water content state of soil (experimental data from Vanapalli et al. [10]).

The suction stress can also be obtained from triaxial shear tests according to Mohr-Coulomb criterion. The formula is given as follows:

$$
\begin{aligned}
\sigma_{S}= & -\frac{\sigma_{1}^{\prime}-p^{N}}{2 \tan \left(\pi / 4+\varphi^{\prime} / 2\right) \tan \varphi^{\prime}} \\
& +\frac{\left(\sigma_{3}^{\prime}-p^{N}\right) \tan \left(\pi / 4+\varphi^{\prime} / 2\right)}{2 \tan \varphi^{\prime}}+\frac{c^{\prime}}{\tan \varphi^{\prime}},
\end{aligned}
$$

where $\sigma_{1}^{\prime}$ and $\sigma_{3}^{\prime}$ are the major and minor principle stress, respectively.
The new effective stress can be defined based on suction stress as follows:

$$
\sigma^{\prime}=\left(\sigma-p^{N}\right)-\sigma_{S}
$$

where $\sigma^{\prime}$ is the effective stress and $\sigma$ is the total stress. In order to verify the expression of effective stress is reasonable, the experimental data of shear strength or deformation tests of unsaturated soils could be used.

Sandy-clay till was used to do shear strength test at three types of water content state by Vanapalli et al. [10]. Shear failure envelops go upward drift with matric suction increasing, which is shown in Figure 2(a). Simultaneously, Figures 2(a), 2(b), and 2(c) show that the shear strengths are 


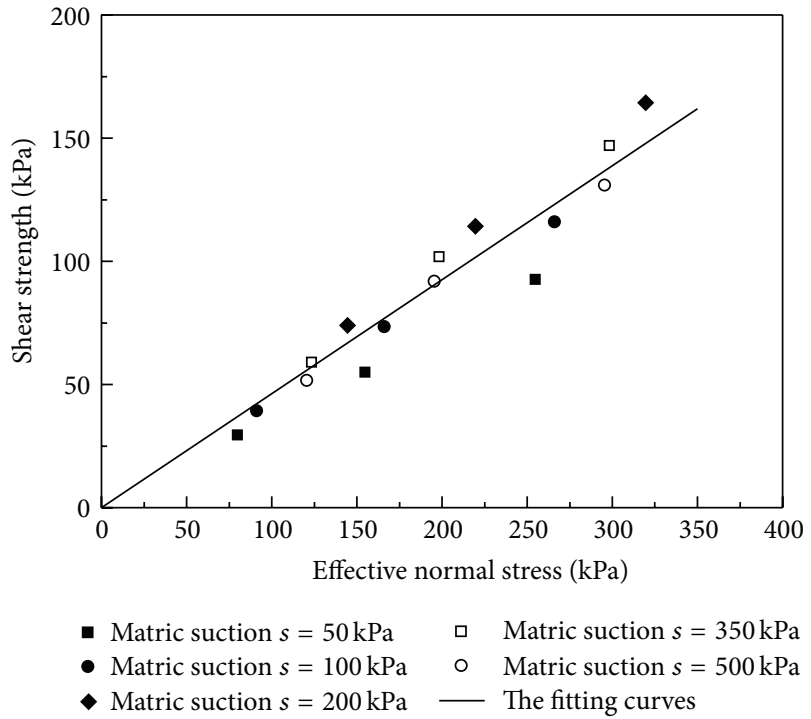

(a) Modified shear strength envelops at drier than optimum water content

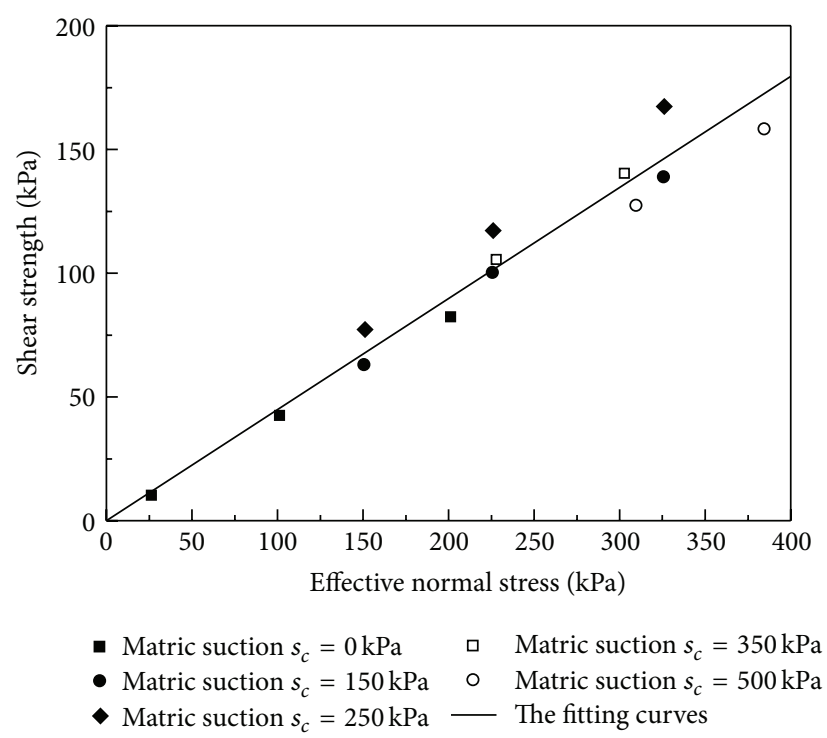

(b) Modified shear strength envelops at wetter than optimum water content

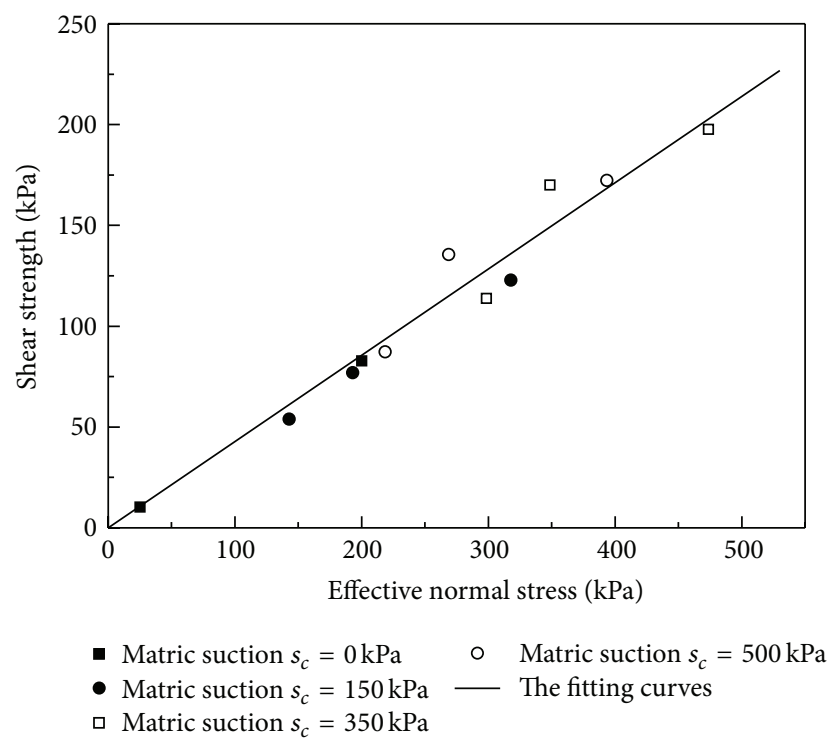

(c) Modified shear strength envelops at optimum water content

Figure 3: The curves of effective normal stress and shear strength at different initial water content state of soil (experimental data from Vanapalli et al. [10]).

not the same, although the matric suction and normal stress are completely identical. The unique difference is the initial state of the soils. The shear strength is largest at wetter than optimum water content state, and it is smallest at drier than optimum water content state. Obviously, the shear strength of unsaturated soils $\tau$ is strongly depended on the state of water content. We can obtain suction stresses from Formula (3) or (4) using the tested data from Figures 2(a), 2(b), and 2(c). Then the new effective stress is achieved. The strength failure envelops are redrawn in the plane $\sigma^{\prime}-\tau$ in Figure 3 .

It is interesting that these data points at failure state tend to a line. The phenomenon is not coincidental. There are many measured data from literatures that are not given due to the limited space of this paper, which can be seen detailedly in the literature $[21,22]$. That is to say, the critical state failure envelop is unique under the new effective stress framework of unsaturated soils. And the effective stress can be also used for saturated soils, which is coincident with Terzaghi's effective theory. The new effective stress is the reasonable one with suction stress. The problem of nonunique failure envelops of unsaturated soils in traditional framework is solved by the new effective stress framework. The meaning of effective stress with suction stress is clear in the framework of continuum mechanics. And it is deduced that the properties in deformation and strength of unsaturated soils could be described in the unified way by the mathematics Formula (5). 
2.2. Suction Strength of Unsaturated Soils. The shear strength equation of unsaturated soils is obtained based on the effective stress Formula (5):

$$
\tau_{f}=c^{\prime}+\left(\sigma-p^{N}-\sigma_{S}\right) \tan \varphi^{\prime},
$$

where $c^{\prime}$ and $\varphi^{\prime}$ are the effective cohesion and the effective internal friction angle at saturated state, respectively.

Suction stress is macrorepresentation of interaction of soil particles in microscale, which increases the attraction of soil skeleton and shear strength. Compared with saturated soil, there is a difference that the shear strength is related to water content. The change of strength due to the fluctuate of water content is defined as suction strength $c_{S}^{\prime}$ :

$$
c_{S}=-\sigma_{S} \tan \varphi^{\prime}
$$

Based on these literatures [11-13], the suction strength can be obtained from the shear strength tests. The apparent cohesion $c$ is defined as

$$
c=c^{\prime}+c_{S}
$$

The shear strength equation can be modified as follows:

$$
\tau_{f}=c+\left(\sigma-p^{N}\right) \tan \varphi^{\prime} .
$$

The equation is coincident with the one of saturated soils in form. Therefore, the shear strength of unsaturated and saturated soils can be both expressed by Formula (9). The formula of shear strength is obtained in the unified framework of soils, in which new empirical parameters are not introduced.

\section{Shear Strength Model of Unsaturated Soils Depending on Hydraulic State}

The suction stress is related to water content of unsaturated soils from the above analyses. The relationship is derived by Lu et al. [21] based on the principles of thermodynamics:

$$
\sigma_{S}=-S_{e}\left(p^{N^{\prime}}-p^{W}\right)
$$

where $p^{W}$ is the water pressure and matric suction $s_{c}$ is defined as follows:

$$
s_{c}=p^{N^{\prime}}-p^{W}
$$

$S_{e}$ is the effective degree of saturation:

$$
S_{e}=\frac{\left(S_{r}-S_{r}^{\mathrm{irr}}\right)}{\left(1-S_{r}^{\mathrm{irr}}\right)},
$$

where $S_{r}$ is the degree of saturation and $S_{r}^{\text {irr }}$ is the residual degree of saturation.

Introducing Formulas (10), (11), and (12) to Formulas (7) and (9), the suction strength and shear strength equations can be given as follows:

$$
\begin{gathered}
c_{S}=S_{e} s_{c} \tan \varphi^{\prime}, \\
\tau_{f}=c^{\prime}+S_{e} s_{c}+\left(\sigma-p^{N}\right) \tan \varphi^{\prime} .
\end{gathered}
$$

As seen from Formula (14), the shear strength of unsaturated soils is only related to the degree of saturation but also related to matric suction. The relationship of the shear strength and matric suction (the degree of saturation) can be obtained by introducing the soil-water retention curve (SWRC). The change of soil-water state is generally not monotonic under intermittent precipitation and fluctuating water tables. The capillary hysteresis (hydraulic hysteresis) often exits during the increment and decrement of water content in the seepage process of unsaturated soils. Capillary hysteresis refers to the nonunique relationship between the degree of saturation and matric suction and describes the irreversible changes in the degree of saturation occurring during the preceding sequence of drying and wetting of a porous medium. The importance of hysteretic effect (hydraulic hysteresis) in the unsaturated flow has been found in the literatures [23]. Furthermore, hysteretic effect can also significantly influence the shear strength and the shear behaviour, as seen in works such as those performed by Kwong [24] and Khoury and Miller [25]. Kwong [24] found that the strengths of unsaturated soils getting wetter are lower than those getting drier. Khoury and Miller [25] found that shear strength following a drying/wetting process was higher than that for the drying process alone at the similar matric suction and net normal stress. These results give an important conclusion that the water content and matric suction are of equal importance to obtain the shear strength of unsaturated soils. The two soil-water state parameters are affected by the hydraulic hysteresis. The effect of hysteresis should be considered in the analysis of the strength problems related to unsaturated soils.

In order to conclude the hysteretic effect in the shear strength problems, the hysteretic soil-water relationship should be developed for constructing the shear strength model of unsaturated soils. There are some methods which may be used to consider hysteretic effect during the process of the water content change history [26-28]. The main object of this paper is to develop a new strength model to reproduce the change of shear strength that underwent the effect of capillary hysteresis in unsaturated soils. Recently, a capillary hysteretic model with internal state variables (ISVH-model) was developed by Wei and Dewoolkar [18]. The boundary surface plasticity theory is used to model the hysteretic behavior of the soil water retention curves. In this model, the arbitrary water content variable path can be traced between the main boundary curves. The equations of the model are presented here for the integrality of this paper. Feng and Fredlund [29] offered an equation which was used to well fit the boundary curves of the soil water retention curves. The main drying curve is

$$
S_{r D}=\frac{1+S_{r D}^{\mathrm{irr}}\left(s_{c} / b_{D}\right)^{a_{D}}}{1+\left(s_{c} / b_{D}\right)^{a_{D}}},
$$

and the main wetting curve is

$$
S_{r W}=\frac{1+S_{r W}^{\mathrm{irr}}\left(s_{c} / b_{W}\right)^{a_{W}}}{1+\left(s_{c} / b_{W}\right)^{a_{W}}},
$$




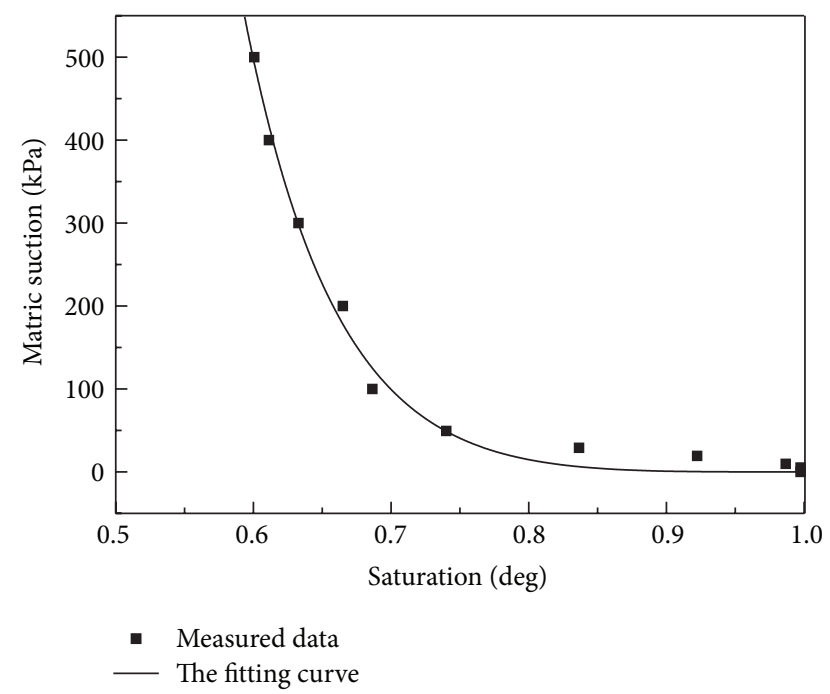

FIGURE 4: The fitting tested curve of SWRC for the completely decomposed granite soil (measured data from Hossain and Yin [20]).

where $S_{r D}$ and $S_{r W}$ are the degrees of saturation of the drying and wetting boundaries, respectively; $S_{r D}^{\mathrm{irr}}$ and $S_{r W}^{\mathrm{irr}}$ are the residual degrees of saturation at the drying and wetting conditions, respectively; $b_{D}, a_{D}, b_{W}$, and $a_{W}$ are the four material parameters.

The evolution equation of the degree of saturation that underwent the drying and wetting cycles is described as follows:

$$
\dot{S}_{r}=-\frac{\dot{s}_{c}}{K_{p}\left(S_{r}, s_{c}, \widehat{n}\right)},
$$

where $\widehat{n}$ is the direction of the hydraulic path and its value is -1 or 1 . For the wetting path, $\widehat{n}=-1$, and for the drying path, $\widehat{n}=1 ; K_{p}\left(S_{r}, s_{c}, \widehat{n}\right)$ is given as follow:

$$
K_{p}\left(S_{r}, s_{c}, \widehat{n}\right)=\bar{K}_{p}\left(S_{r}, \widehat{n}\right)+\frac{d\left|s_{c}-\bar{s}_{c}\left(S_{r}, \widehat{n}\right)\right|}{r\left(S_{r}^{W}\right)-\left|s_{c}-\bar{s}_{c}\left(S_{r}, \widehat{n}\right)\right|},
$$

where $d$ is a fit parameter, which is an additional parameter to describe all of the scanning curves in the hysteretic cycle; matric suction in the main drying and wetting boundary curves is expressed by $\bar{s}_{c}=\kappa_{D}\left(S_{r}\right)$ and $\bar{s}_{c}=$ $\kappa_{W}\left(S_{r}\right)$, respectively; $r\left(S_{r}\right)$ is the difference of the matric suction between the main boundary curves when the soil water state is at the degree of saturation $S_{r}, r\left(S_{r}\right)=$ $\kappa_{D}\left(S_{r}\right)-\kappa_{W}\left(S_{r}\right) ; \bar{K}_{p}$ and $\bar{s}_{c}\left(S_{r}, \widehat{n}\right)$ are respectively the slope and matric suction of the main drying and wetting boundary curves as follows.

(1) Drying path $(\widehat{n}=1)$ :

$$
\bar{s}_{c}\left(S_{r}, 1\right)=\kappa_{D}\left(S_{r}\right), \quad \bar{K}_{p}\left(S_{r}, 1\right)=\frac{d \kappa_{D}\left(S_{r}\right)}{d S_{r}} .
$$

(2) Wetting path $(\widehat{n}=-1)$ :

$$
\bar{s}_{c}\left(S_{r},-1\right)=\kappa_{W}\left(S_{r}\right), \quad \bar{K}_{p}\left(S_{r},-1\right)=\frac{d \kappa_{W}\left(S_{r}\right)}{d S_{r}^{W}} .
$$

Introducing the hysteretic model (ISVH), suction strength and shear strength are expressed as follows:

$$
\begin{gathered}
c_{S}=s_{c} \tan \varphi^{\prime}, \quad s_{c} \leq 0, \\
c_{S}=S_{e}\left(\dot{S}_{r}\right) s_{c} \tan \varphi^{\prime}, \quad s_{c}>0, \\
\tau_{f}=c^{\prime}+\left(\sigma-p^{N}\right) \tan \varphi^{\prime}+s_{c} \tan \varphi^{\prime}, \quad s_{c} \leq 0, \\
\tau_{f}=c^{\prime}+\left(\sigma-p^{N}\right) \tan \varphi^{\prime}+S_{e}\left(\dot{S}_{r}\right) s_{c} \tan \varphi^{\prime}, \quad s_{c}>0
\end{gathered}
$$

If the current soil-water state $\left(s_{c}, S_{r}\right)$ and the increment of the degree of saturation $\dot{S}_{r}$ are given, the change of shear strength of unsaturated soils can be predicted by Formulas (20a) and (20b) during any drying/wetting cycle, combined with the shear strength of saturated soils $\left(c^{\prime}\right.$ and $\left.\varphi^{\prime}\right)$.

\section{Model Verification}

The suction strength and shear strength of unsaturated soils are predicted based on Formulas (18a), (18b), (20a), and (20b). And the predictive curves are compared with experimental strength data. The parameters of soil-water retention curves from fitting the measured soil-water data are used to predict the change of shear strength.

4.1. Strength Property under Single Drying Hydraulic Path. The soil-water retention curve and direct shear strength tests of unsaturated completely decomposed granite soil are performed in the laboratory by Hossain and Yin [20]. The measured soil-water retention curve is given in Figure 4. And the shear strength parameters at saturated state are $c^{\prime}=$ $0.0 \mathrm{kPa}$ and $\varphi^{\prime}=29.9^{\circ}$. Formula (15a) is adopted to fit the measured soil-water data for the drying process alone. The fitting curve is also shown in Figure 4. And the parameters of the soil-water retention curve are listed in Table 1. Formulas (19b) and (20b) are adopted to predict the suction strength and shear strength of the soils, combining with the shear strength parameters at saturated state. The predictive curves are shown in Figure 5. The coincidence of suction strength is well under low suction conditions. And a little deviation comes out in high suction conditions (Figure 5(a)). The prediction of shear strength of the soils is acceptable at low effective stresses. However, the deviation between measured data and the predictive curve is large at higher effective stresses. The similar results are shown by Hossain and Yin [20]. The distinct dilative behavior of unsaturated compacted completely decomposed granite soil was observed in the measurement by Hossain and Yin [20]. The apparent cohesion intercept and angle of internal friction increase with matric suction due to the effect of dilative behavior. It is to be note that the effective stress is obtained based on Formula (5) (Figure 5(b)).

The same method is also adopted to predict shear strength of Diyarbakir residual clays. The shear strength and soil-water 


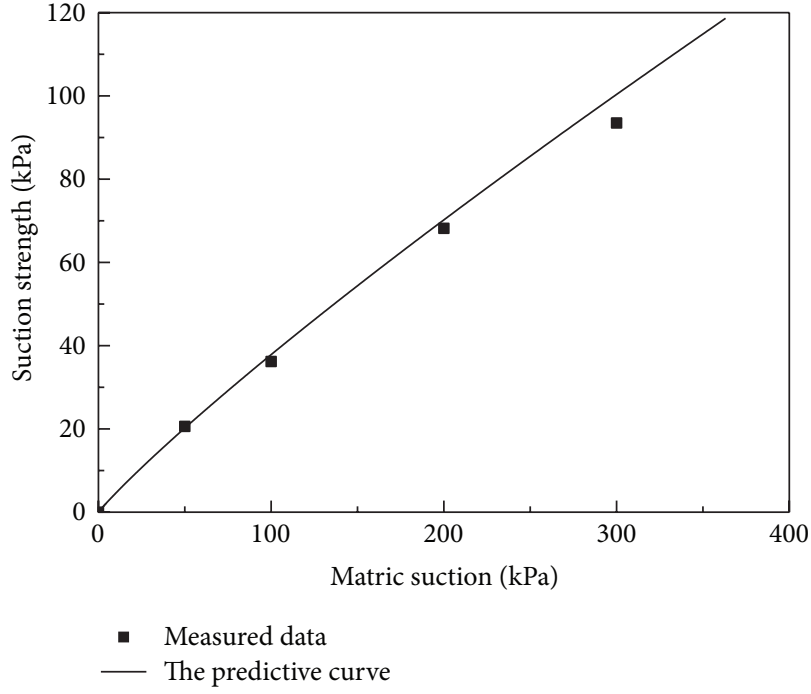

(a) Suction strength

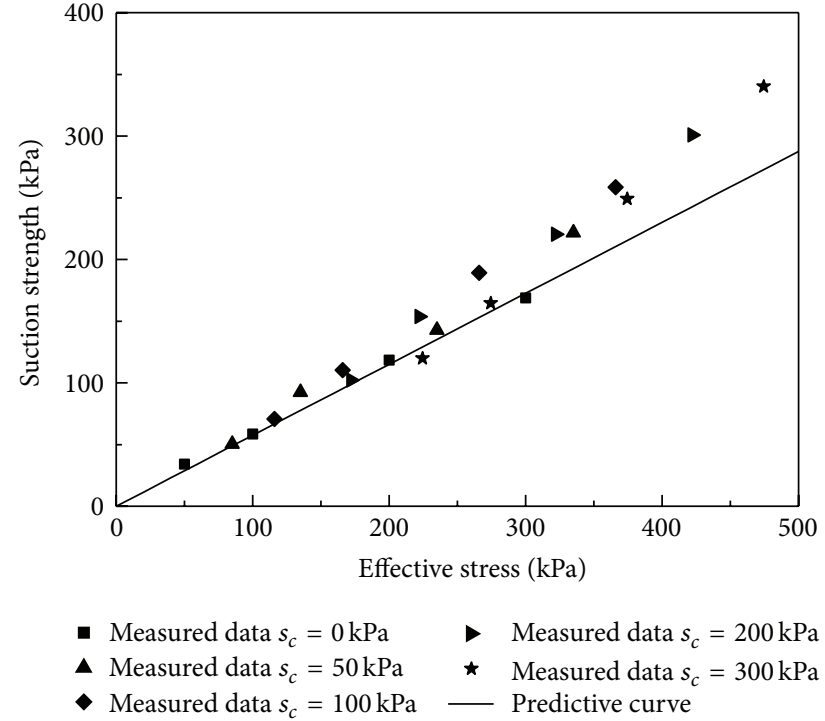

(b) Shear strength

Figure 5: Comparison of tested data with the predictive curve of suction strength and shear strength (measured data from Hossain and Yin [20]).

TABLE 1: Parameters of SWRC of unsaturated soil and shear strength of saturated soil for predicting suction strength of unsaturated soils that underwent single drying hydraulic path.

\begin{tabular}{|c|c|c|c|c|c|c|}
\hline \multirow{2}{*}{ Soil types } & \multicolumn{4}{|c|}{ Parameters of SWRC } & \multicolumn{2}{|c|}{ Strength parameters } \\
\hline & $n$ & $S_{r}^{\mathrm{irr}}$ & $a$ & $b(\mathrm{kPa})$ & $c^{\prime}(\mathrm{kPa})$ & $\varphi^{\prime}$ \\
\hline Completely decomposed granite soil & 0.36 & 0.120 & 0.2961 & 917.35 & 0 & 29.9 \\
\hline Diyarbakir residual clays & 0.581 & 0.442 & 0.4679 & 488.74 & 14.82 & 21.9 \\
\hline
\end{tabular}

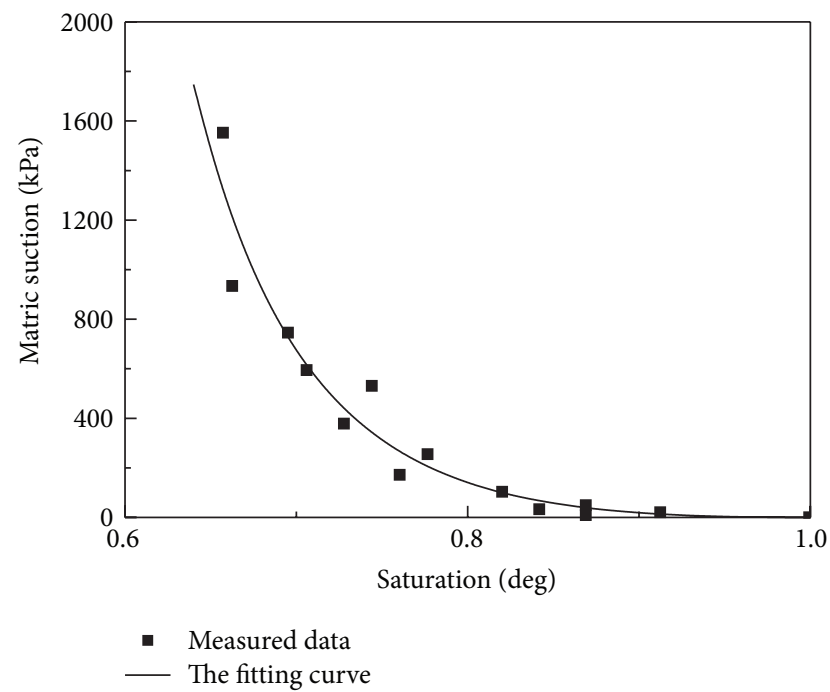

FIGURE 6: The fitting tested curve of SWRC for Diyarbakir residual clays (measured data from Kayadelen et al. [12]).

retention tests are performed by Kayadelen et al. [12]. The fitting soil-water retention curve is shown in Figure 6. And the parameters of the soil-water retention curve are listed in Table 1. The shear strength parameters of Diyarbakir residual clays at saturated state are $c^{\prime}=14.82 \mathrm{kPa}$ and $\varphi^{\prime}=21.9^{\circ}$. The predictive curves of suction strength and shear strength of the residual clays are shown in Figure 7. As seen from Figures 7(a) and $7(\mathrm{~b})$, the suction strength and shear strength both well match up to experimental data. The distribution of the shear strength data at different matric suctions is approximately linear again in Figure 7(b). The critical state failure is unique under the new effective stress state based on suction stress. It does not exist that the failure envelops are nonunique, based on the new shear strength model.

4.2. Strength Property under Drying/Wetting Paths. The shear strength is very important for predicting the slope stability under the intermittent precipitation conditions, for example, Gvirtzman et al. [30]. The variation in strength of unsaturated soils will be studied in the section under the repeating change of water content conditions. However, the measured data of shear strength that underwent drying/wetting process are little seen in the literature. The main reasons are that the test instruments are not well established and these experiments are time-consuming in the laboratory.

Goh et al. [5] performed a series of unsaturated consolidation drained triaxial tests under drying and wetting, in which compacted sand-kaolin specimens were adopted. The soil-water retention curves are also measured by tempecell and pressure plate in Goh et al. [5]. The $c^{\prime}$ and $\varphi^{\prime}$ of 


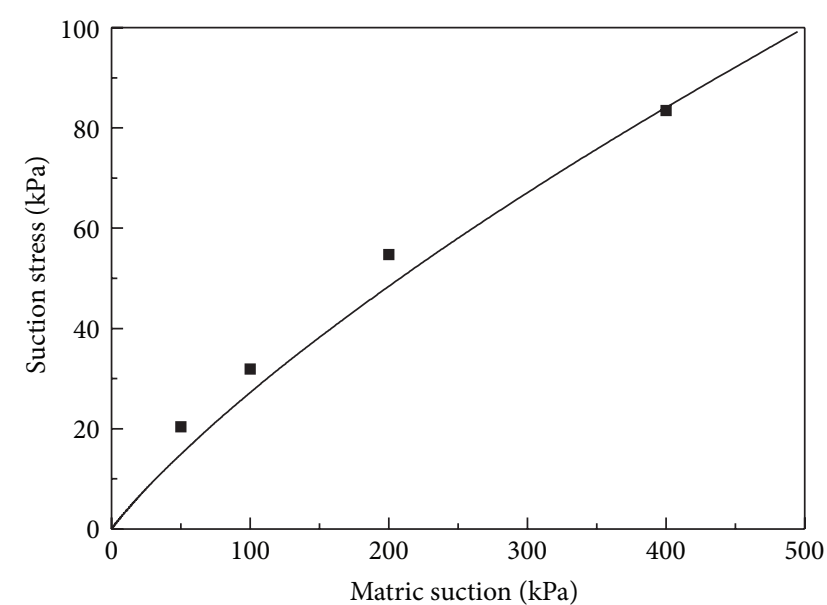

- Experimental data

- The predictive curve

(a) Suction strength

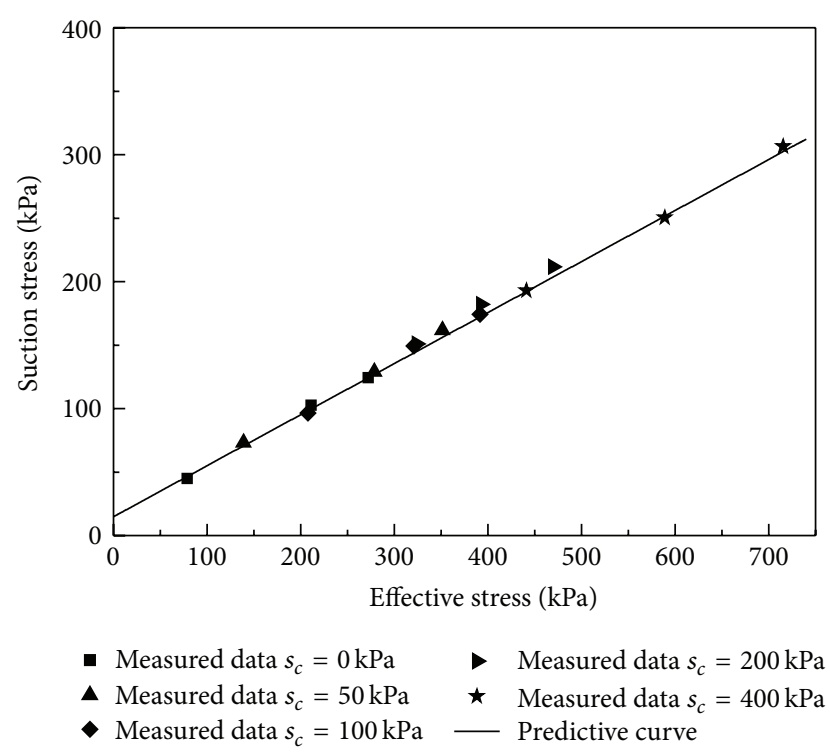

(b) Shear strength

FIGURE 7: Comparison of tested data with the predictive curve of suction strength and shear strength (measured data from Kayadelen et al. [12]).

TABLE 2: Parameters of SWRC of unsaturated soil and shear strength of saturated soil for predicting suction strength of unsaturated soils that underwent drying/wetting paths.

\begin{tabular}{lccccccccccc}
\hline \multirow{2}{*}{ Soil types } & \multicolumn{4}{c}{ Parameters of SWRC } & \multicolumn{4}{c}{ Strength parameters } \\
& $n$ & $S_{r D}^{\text {irr }}$ & $a_{D}$ & $b_{D}(\mathrm{kPa})$ & $S_{r W}^{\text {irr }}$ & $a_{W}$ & $b_{W}(\mathrm{kPa})$ & $d$ & $c^{\prime}(\mathrm{kPa})$ & $\varphi^{\prime}$ \\
\hline Sand-kaolin mixture & 0.470 & 0.055 & 0.566 & 1520.30 & 0.055 & 0.481 & 874.81 & 19620.0 & 8.5 & 26.9 \\
\hline
\end{tabular}

the compacted saturated sand-kaolin mixture are $8.5 \mathrm{kPa}$ and $26.9^{\circ}$, respectively. The soil-water retention data and the fitting curves are given in the Figure 8 . The main drying and main wetting curve are fitted by Formulas (15a) and (15b), respectively. The wetting scanning data are used to correct the parameter $d$ in Formula (17). Then the parameter $d$ is adopted to predict the drying scanning curve. The parameters for fitting SWRC are listed in Table 2.

The parameters of the main drying and wetting curves and the parameter $\mathrm{d}$ are used to predict the change of suction strength of the unsaturated sand-kaolin mixture that underwent the drying/wetting cycle. The predictive results are presented in Figure 9. The suction strength obtained from the drying process was predicted by these parameters of the main drying and drying scanning curves, respectively. The coincidence is well compared with the measured data. At the low suction state, the predictive curve is much nearer the measured results using the parameters from the drying scanning curve than those from the main drying curve. However, the tendency of the predictive curves is the same at the high suction state. That is, due to that the drying scanning curve and the main drying curve are coincident at the high suction condition, seen in Figure 8. The similar comparisons were done between the measured suction strength from the wetting process with the predictive curves. The predictive tendency from the wetting process is different from the one from the drying state. At the high suction state, the predictive curve is much nearer the measured results using the parameters from the wetting scanning curve than those from the main wetting curve. However, the tendency of the predictive curves is also the same at the low suction state. That is, due to that the wetting scanning curve and the main wetting curve are coincident at the high suction condition, which can be also seen in Figure 8. The soil-water state is not always along the main boundary curves due to hysteretic effect. The soil-water state is perhaps along the scanning drying or wetting curve at the shear strength tests. Hence, the predictive results by the scanning curves are nearer to the measured strength data than the ones by the main boundary curves.

It noted to say that the correlation of suction strength and soil-water state is evident, seen in Figure 9. Furthermore, the difference of suction strength is increasing with the increment of matric suction for the drying or wetting path. And the suction strength along the drying path is larger than the ones along the wetting path. That is to say, the shear strength is closely related to the water content and matric suction. Due to the existence of hysteretic effect, the water content may be different at the same matric suction through different drying/wetting paths. The shear strength will be different, though the matric suction is the same. Hence, it is indispensable that the research work should be carried out on the change of shear strength of unsaturated soils that underwent the repeating changes of water content. 


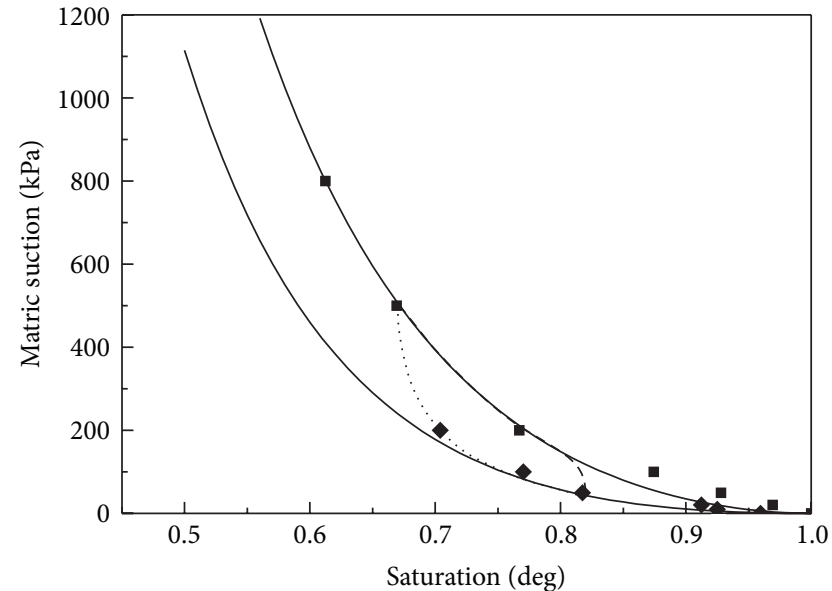

- Measured main drying data __ Fitting main wetting data

- Measured main wetting data $\quad . .$. . Corrected the parameter $d$

_ Fitting main drying data _ - - Predicted the scanning curve

FIGURE 8: The fitting tested curve of SWRC for sand-kaolin mixture (measured data from Goh et al. [5]).

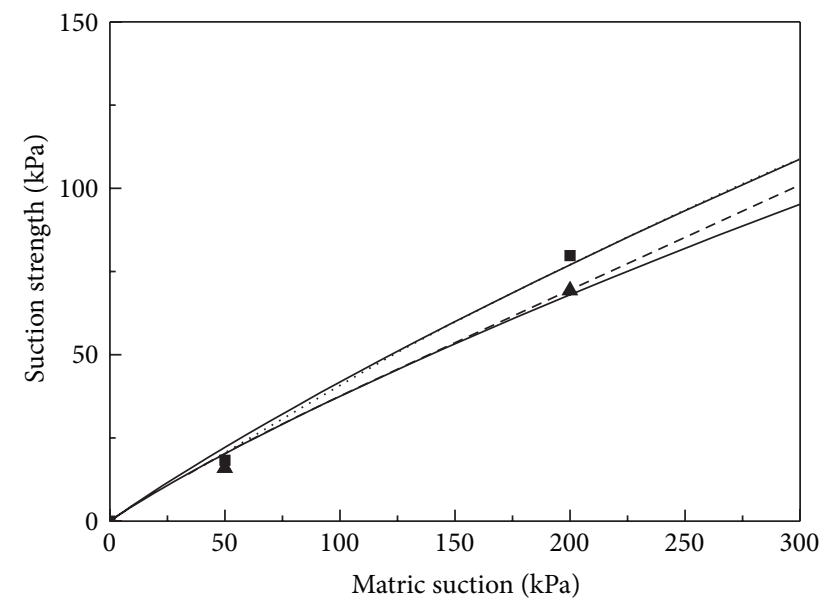

- Measured data along drying path

- Measured data along wetting path

- Predicted curve using the main drying curve

- Predicted curve using the main wetting curve

- - - Predicted curve using the wetting scanning curve

..... Predicted curve using the wetting scanning curve

FIGURE 9: Comparison of tested data with the predictive curve of suction strength under drying-wetting paths (measured data from Goh et al. [5]).

\section{Conclusions}

The theoretical strength model is developed based on the concept of suction stress. The predictive curves of the model are compared with experimental data. And its validity of the strength model is verified. There are some conclusions as follows.

(1) Suction stress is the macroscopic effect of many different microscopic forces in unsaturated soils. Redundant parameters need not to be introduced to describe these microscopic forces, respectively. The effective stress framework of unsaturated soils is improved. The failure envelop of unsaturated soils is unique at different matric suction and net normal stresses, based on the new effective stress framework. The cohesion arisen by tension among soil particles expresses its real concept. The relation of matric suction and suction stress can be uniquely expressed by the suction stress characteristic curve (SSCC), which is very important for describing the stress state, similar with SWRC for describing the soil-water state. The uncertainty of the parameters of shear strength of soils can be avoided in the effective stress frame.

(2) In the new strength model, the SWRC and SSCC are combined to predict the change of shear strength of unsaturated soils under repeated water content (matric suction) change. The SWRC is used to predict the change of suction strength and shear strength of unsaturated soils. The SWRC is widely adopted in geotechnical engineering and soil physics. The parameters of SWRC are much easier to obtain in laboratory or field, compared with the shear strength tests of unsaturated soils. Furthermore, the time can be saved largely once the SWRC is used to predict the strength of unsaturated soils, especially for fine gained soils.

(3) The predictive curves of suction strength and shear strength of the soils both well match up to experimental data for the completely decomposed granite soil and Diyarbakir residual clays that underwent single drying paths. Furthermore, the coincidence is well compared with the measured suction strength for the sand-kaolin mixture under the repeated change of water content. Hence, the new strength theory model with suction effective concept is validated for predicting the change of shear strength of unsaturated soils that underwent the fluctuation of water content. In the new strength model, only the parameters of SWRC of unsaturated soils and shear strength of saturated soil were used to predict the change of shear strength of unsaturated soils under the arbitrary change of water content.

(4) Based on the measured strength data and predictive curves, the shear strength is closely related to the water content and matric suction. The shear strength can be different at the same matric suction due to the existence of hysteretic effect. Hence, hysteretic effect in the seepage process should be considered to predict the change of shear strength of unsaturated soils that underwent drying/wetting cycles.

\section{Acknowledgments}

The research is supported by the National Natural Science Foundation of China (11302243, 11072255), the Natural Science Foundation of GuangXi (no. 2011 GXNSFE018004), and the planed major science and technology projects of Zhejiang (no. 2009C13010).

\section{References}

[1] J. E. B. Jennings and J. B. Burland, "Limitations to the use of effective stresses in partly saturated soils," Geotechnique, vol. 12, no. 2, pp. 125-144, 1962. 
[2] D. G. Fredlund, N. R. Morgenstern, and R. A. Widger, "Shear strength of unsaturated soils," Canadian Geotechnical Journal, vol. 15, no. 3, pp. 313-321, 1978.

[3] S. K. Vanapalli, D. E. Pufahl, and D. G. Fredlund, "The effect of stress state on the soil-water characteristic behavior of a compacted sandy-clay till," in Proceedings of the 51st Canadian Geotechnical Conference, pp. 81-86, 1998.

[4] L. Cao and X.-Q. Luo, "Experimental study of dry-wet circulation of Qianjiangping Landslide's unsaturated soil," Rock and Soil Mechanics, vol. 28, pp. 93-97, 2007 (Chinese).

[5] S. G. Goh, H. Rahardjo, and E. C. Leong, "Shear strength equations for unsaturated soil under drying and wetting," Journal of Geotechnical and Geoenvironmental Engineering, vol. 136, no. 4, pp. 594-606, 2010.

[6] A. W. Bishop, "The principle of effective stress," Teknisk Ukeblad, vol. 106, no. 39, pp. 859-863, 1959.

[7] D. G. Fredlund and N. R. Morgenstern, "Stress state variables for unsaturated soils," Journal of the Geotechnical Engineering Division, vol. 103, no. 5, pp. 447-466, 1977.

[8] N. Khalili, F. Geiser, and G. E. Blight, "Effective stress in unsaturated soils: review with new evidence," International Journal of Geomechanics, vol. 4, no. 2, pp. 115-126, 2004.

[9] N. Lu, "Is matric suction a stress variable?" Journal of Geotechnical and Geoenvironmental Engineering, vol. 134, no. 7, pp. 899905, 2008.

[10] S. K. Vanapalli, D. G. Fredlund, D. E. Pufahl, and A. W. Clifton, "Model for the prediction of shear strength with respect to soil suction," Canadian Geotechnical Journal, vol. 33, no. 3, pp. 379392, 1996.

[11] N. Khalili and M. H. Khabbaz, "A unique relationship for $\chi$ for the determination of the shear strength of unsaturated soils," Geotechnique, vol. 48, no. 5, pp. 681-687, 1998.

[12] C. Kayadelen, M. A. Tekinsoy, and T. TaşkIran, "Influence of matric suction on shear strength behavior of a residual clayey soil," Environmental Geology, vol. 53, no. 4, pp. 891-901, 2007.

[13] A. L. Oberg and G. Sallfors, "Determination of shear strength parameters of unsaturated silts and sands based on the water retention curve," Geotechnical Testing Journal, vol. 20, no. 1, pp. 40-48, 1997.

[14] L. Miao, S. Liu, and Y. Lai, "Research of soil-water characteristics and shear strength features of Nanyang expansive soil," Engineering Geology, vol. 65, no. 4, pp. 261-267, 2002.

[15] Y. F. Xu, "Fractal approach to unsaturated shear strength," Journal of Geotechnical and Geoenvironmental Engineering, vol. 130, no. 3, pp. 264-273, 2004.

[16] N. Lu and W. J. Likos, Unsaturated Soil Mechanics, John Wiley, New York, NY, USA, 2004.

[17] D. Tami, H. Rahardjo, and E.-C. Leong, "Effect of hysteresis on steady-state infiltration in unsaturated slopes," Journal of Geotechnical and Geoenvironmental Engineering, vol. 130, no. 9, pp. 956-967, 2004.

[18] C. F. Wei and M. M. Dewoolkar, "Formulation of capillary hysteresis with internal state variables," Water Resources Research, vol. 42, Article ID W07405, 2006.

[19] N. Lu and W. J. Likos, "Suction stress characteristic curve for unsaturated soil," Journal of Geotechnical and Geoenvironmental Engineering, vol. 132, no. 2, pp. 131-142, 2006.

[20] M. A. Hossain and J.-H. Yin, "Shear strength and dilative characteristics of an unsaturated compacted completely decomposed granite soil," Canadian Geotechnical Journal, vol. 47, no. 10, pp. 1112-1126, 2010.
[21] N. Lu, J. W. Godt, and D. T. Wu, "A closed-form equation for effective stress in unsaturated soil," Water Resources Research, vol. 46, Article ID W05515, 2010.

[22] P. Chen, A Study on Seepage and Slope Stability of Unsaturated Soils Subjected to Drying/Wetting Cycles, Institute of Rock and Soil Mechanics; Chinese Academy of Sciences, Wuhan, China, 2011.

[23] C. Yang, D. Sheng, and J. P. Carter, "Effect of hydraulic hysteresis on seepage analysis for unsaturated soils," Computers and Geotechnics, vol. 41, pp. 36-56, 2012.

[24] H. K. Kwong, Effect of hysteresis, infiltration and tensile stress on the strength of an unsaturated soil [Ph.D. thesis], Nanyang Technological University, Singapore, 1997.

[25] C. N. Khoury and G. A. Miller, "Influence of hydraulic hysteresis on the shear strength of unsaturated soils and interfaces," Geotechnical Testing Journal, vol. 35, no. 1, 2012.

[26] H. Q. Pham, D. G. Fredlund, and S. L. Barbour, "A study of hysteresis models for soil-water characteristic curves," Canadian Geotechnical Journal, vol. 42, no. 6, pp. 1548-1568, 2005.

[27] H.-C. Huang, Y.-C. Tan, C.-W. Liu, and C.-H. Chen, "A novel hysteresis model in unsaturated soil," Hydrological Processes, vol. 19, no. 8, pp. 1653-1665, 2005.

[28] A. Maqsoud, B. Bussiere, M. Aubertin, and M. Mbonimpa, "Predicting hysteresis of the water retention curve from basic properties of granular soils," Geotechnical and Geological Engineering, vol. 30, pp. 1147-1159, 2012.

[29] M. Feng and D. G. Fredlund, "Hysteretic influence associated with thermal conductivity sensor measurements," in Proceeding from Theory to the Practice of Unsaturated Soil Mechanics, 52nd Canadian Geotechnical Conference and Unsaturated Soil Group, Regina, 1999.

[30] H. Gvirtzman, E. Shalev, O. Dahan, and Y. H. Hatzor, "Largescale infiltration experiments into unsaturated stratified loess sediments: monitoring and modeling," Journal of Hydrology, vol. 349 , no. 1-2, pp. 214-229, 2008. 


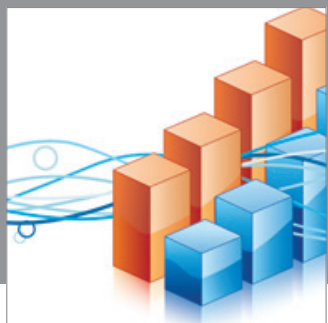

Advances in

Operations Research

mansans

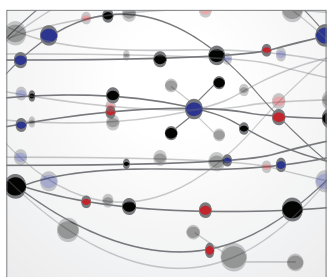

The Scientific World Journal
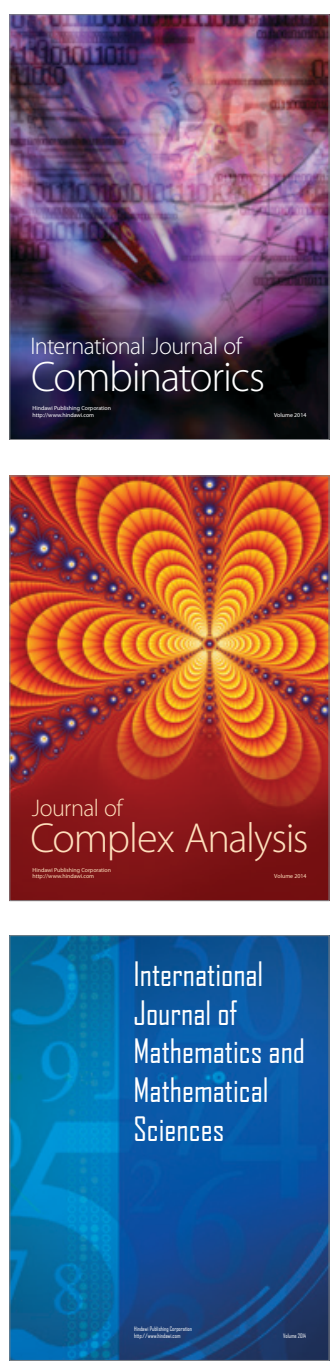
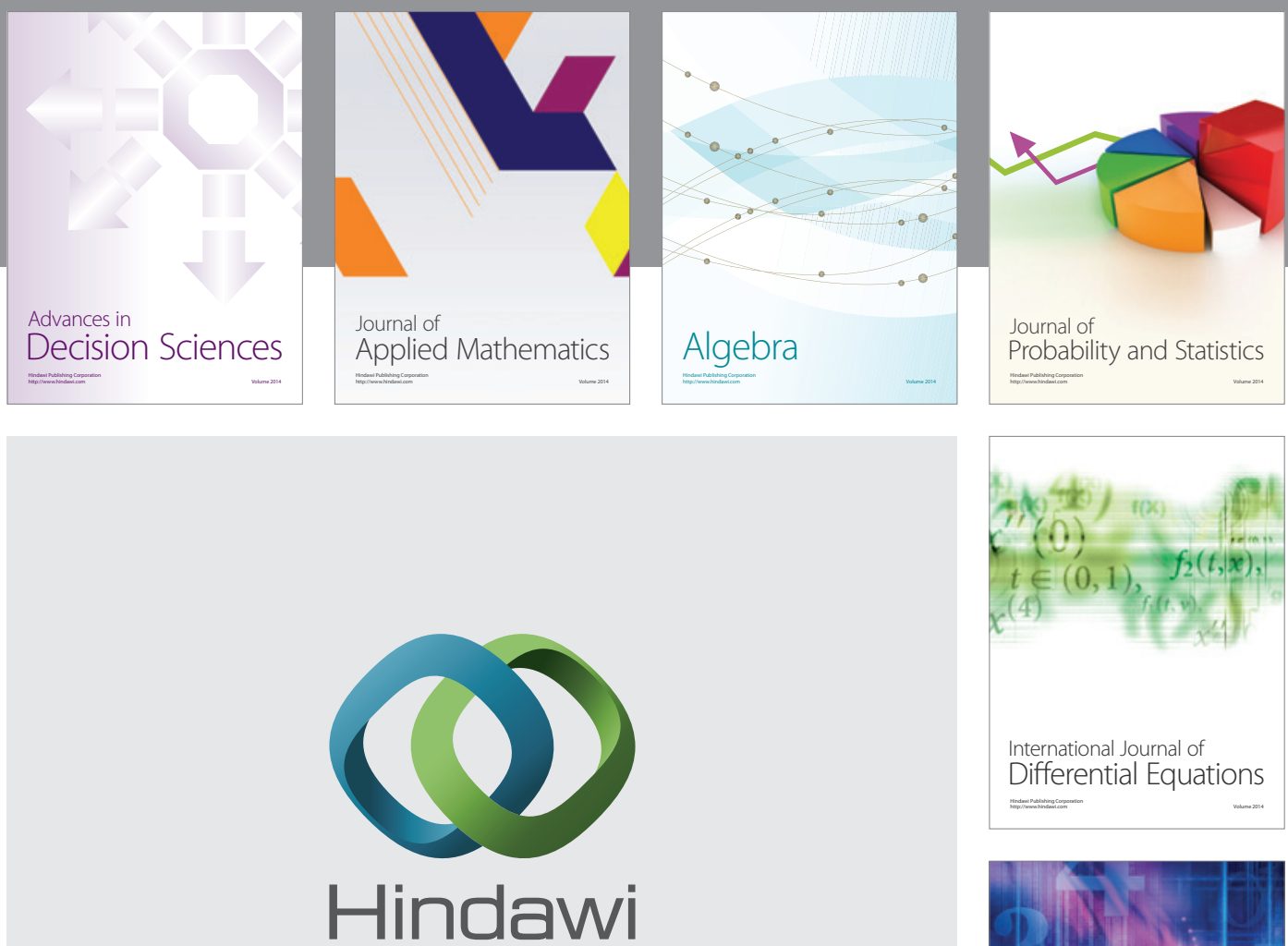

Submit your manuscripts at http://www.hindawi.com
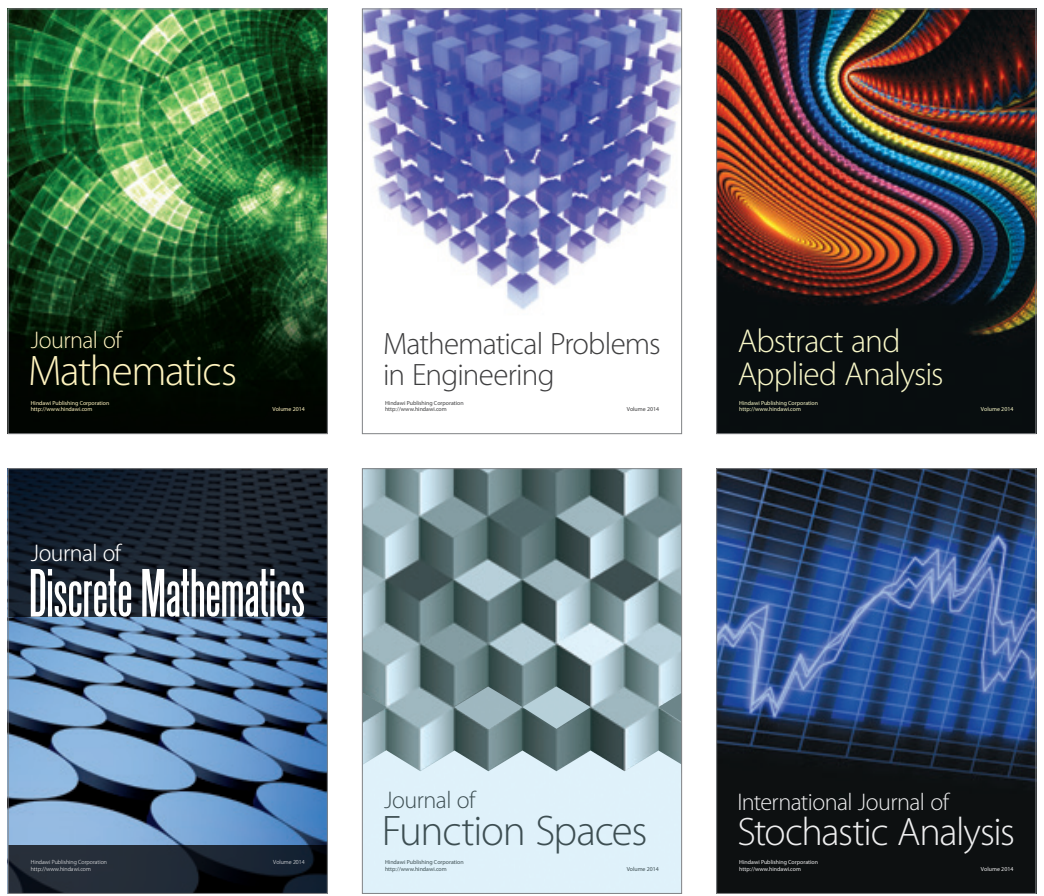

Journal of

Function Spaces

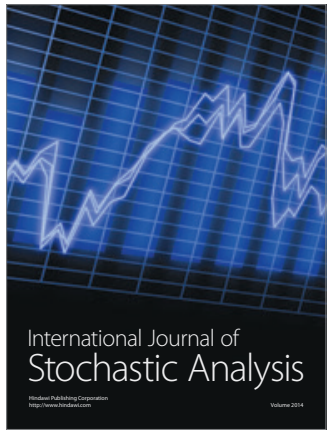

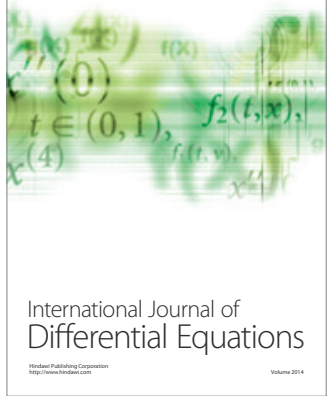
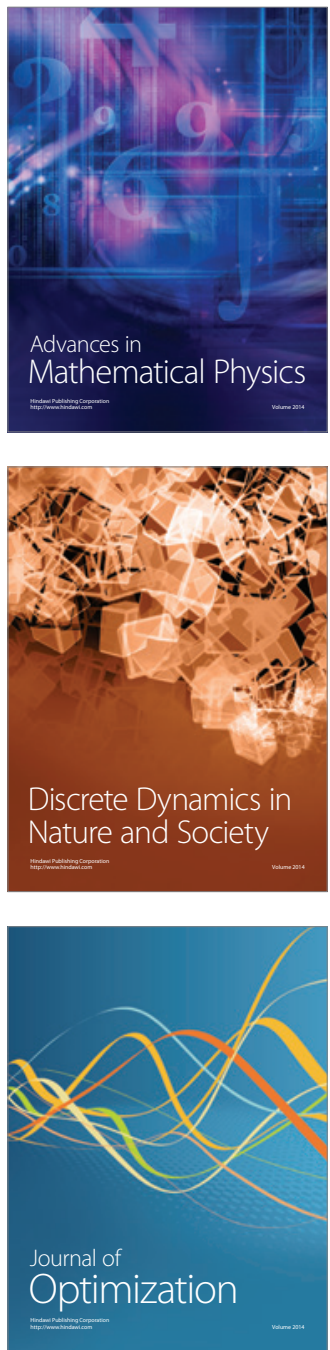